\title{
Clinical Characteristics and Maternal Outcome of Obstetrics Patients Admitted to the Intensive Care Unit: Cross Sectional Observational Study
}

\author{
Tulasi Reddy ${ }^{1}$, K. Rekha Rani ${ }^{2}$, M. Chandramathi ${ }^{3}$, Jyothi Nagasamudram ${ }^{4}$ \\ ${ }^{1,2,3,4}$ Assistant Professor, Department of Obstetrics and Gynaecology, \\ Chalmeda Anand Rao Institute of Medical Sciences \& Hospital, Karimnagar, Telangana.
}

Corresponding Author: K. Rekha Rani

\begin{abstract}
Background: According to UNICEF India, annually 44,000 women die due to preventable pregnancy related causes in India. Globally, this ratio is 830 maternal deaths daily according to a WHO newsletter from 2018. ICU / HDU facility provides simultaneous expert obstetrics care and critical medical care under one roof. The concept of ICU / HDU was introduced as a bridge between routine obstetric care and ICU / HDU in under to bypass and decrease the ICU / HDU burden. ICU / HDU care is required for women requiring more detailed observation, intervention including basic support for a single failing organ system, extended post-op care and those stepping down from higher levels of care. Awareness regarding ICU / HDU care and its benefits need to be improved. This study aims to study the maternal outcome of women admitted in tertiary care hospital, Karimnagar, Telangana.

Methodology: This is cross sectional observational study was conducted in the department of obstetrics and gynaecology at Chalmeda Anand Rao Institute of Medical Sciences and hospital, Karimnagar, Telangana from June 2019 to March 2020 after obtaining clearance from the institutional scientific and ethical committees. In this study total 600 patients were recruited, out of these 150 patients not met the inclusion criteria \& 450 women recruited for questionnaire based proforma, were selected for the study calculated by SPSS 20 software. They have been subjected to thorough history taking, general, obstetric examination and assessment of antenatal records \& management \& their outcome.

Results: The mean age group is 25 yrs. Also found most admission in age group between 20 to $30 \mathrm{yr}$. Most of the cases were belong to low socioeconomic status (99.2\%), Occupationally maximum were unskilled worker $(98.3 \%)$ in present study, Most of the cases were have secondary level of education $(91.6 \%)$. In this present study 180 were hypertensive disorder of pregnancy, followed by 128 were haemorrhage disorder of pregnancy, 108 were
\end{abstract}

medical disorder of pregnancy \& 34 were sepsis. Maternal mortality was $8.7 \%$ in this study.

Conclusion: Commonest cause of mortality was hypertensive disorder of pregnancy \& more than one diagnosis on admission were the other risk factors for ICU / HDU admission. A dedicated ICU / HDU will go a long way in reducing maternal mortality as the responses time from onset of acute severe illness to provision of high quality critical care will be substantially reduced.

Keyword: ICU / HDU, Maternal Outcome, Mortality, Critical Care Unit

\section{INTRODUCTION}

In 2016 national guidelines were provides detailed explanation on ongoing obstetric ICUs / ICU / HDUs, Human Resources requirements, admission discharge criteria and lay outs for the ICUs and ICU / HDUs. WHO states that, "there is a story behind every maternal death or lifethreatening complication". So a better knowledge of the spectrum, characteristics, and outcomes of the disease involving this group of patients is the first step towards achieving prevention and hence, reduction of both maternal morbidity and mortality. ${ }^{(1,2)}$

Management of the critically ill obstetric woman at an ICU is a unique challenge to ICU Physicians and obstetricians. Admission of obstetric patients to ICU occurs approximately at 0.1 $0.9 \%$ of the deliveries. Overall maternal death rate in the ICU varies from 3.4-21\%. Inadequate knowledge about the illness and infrequent admission of the obstetric 
patients results in high mortality and morbidity. ${ }^{(3)}$

According to UNICEF India, annually 44,000 women die due to preventable pregnancy related causes in India. ${ }^{(4)}$ Globally, this ratio is 830 maternal deaths daily according to a WHO newsletter from 2018. ${ }^{(5)}$ Timely intervention and early treatment in patients with high risk pregnancy may reduce further complications i.e. need of intensive monitoring, morbidity and mortality. (3) This indicates need of health care services higher than the traditional obstetric care units. ${ }^{(6)}$

$$
\text { Intensive Care Unit / High }
$$

Dependency Unit (ICU / HDU) is a specially staffed and equipped section of intensive care complex that provides a level of care intermediate between intensive care and general ward care. (7) ICU / HDU facility provides simultaneous expert obstetrics care and critical medical care under one roof. ${ }^{(8)}$ The concept of ICU / HDU was introduced as a bridge between routine obstetric care and ICU in under to bypass and decrease the ICU burden. ${ }^{(9,10)}$ ICU / HDU care is required for women requiring more detailed observation, intervention including basic support for a single failing organ system, extended postop care and those stepping down from higher levels of care. (11,12) Awareness regarding ICU / HDU care and it is benefits need to be improved.

This study was aims to study the maternal outcome of women admitted in tertiary care hospital, Karimnagar, Telangana.

\section{METHODOLOGY}

This is cross sectional observational study was conducted in the department of obstetrics and gynaecology at Chalmeda Anand Rao Institute of Medical Sciences and hospital, Karimnagar, Telangana from June 2019 to March 2020 after obtaining clearance from the institutional scientific and ethical committees. In this study total 600 patients were recruited, out of these 150 patients not met the inclusion criteria \& 450 women recruited for questionnaire based proforma, were selected for the study calculated by SPSS 20 software. They have been subjected to thorough history taking, general, obstetric examination and assessment of antenatal records \& management \& their outcome. All women were included irrespective of period of gestation and postnatal with in 42 delivery requiring admission and who have given consent for the participation for the study. All gynaecology patients were excluded and who did not give consent for the participation in this study.

Data were collected from the ICU records of all pregnant women or admitted women within 6 weeks of delivery admitted over this period were evaluated. In all the major variables included were demographic details, diagnosis, antepartum or postpartum admission, obstetric status, associated medical and surgical condition, referral or inpatient shift to CCU, reason for ICU / HDU \& CCU admission, treatment details, duration of stay, type of intervention, outcome in v/o survival \& mortality.

In the hospital 15 bedded ICU / HDU managed by the anaesthetist and obstetrician with laboratory and blood bank facilities and had facility to transfer other department \& CCU. We had gone through observation regarding of proper obstetric examination, general examination, laboratory investigation \& treatment intervention and follow up. The ICU / HDU admission diagnoses comprised 4 main categories; Hypertensive disorder of pregnancy, Haemorrhage in pregnancy, sepsis \& other medical disorder. Maternal outcome variables came out through this category. Patient were analysed in this categories, according to this patient were shifted as step down \& step up.

\section{STATISTICAL METHODS:}

The data was collected in the prepared proforma and entered into Excel 2016 sheet and analysed with SPSS version 20 IBM software. Results were reported as mean, standard deviation or number 
Tulasi Reddy et.al. Clinical characteristics and maternal outcome of obstetrics patients admitted to the intensive care unit: cross sectional observational study.

percentage \& were calculated for categorical data. There were total 600 admission in the ICU / HDU during the study period. Out of these, 450 women were found eligible after meeting our inclusion criteria \& required ICU / HDU admission. 150 patients excluded because not meeting to inclusion criteria. There was 2 categorisation one was obstetric group (338 patients) and another one was medical group (112) patient.

\section{RESULTS}

Table No. 1: Socio demographic distribution in the study subjects.

\begin{tabular}{|l|l|l|}
\hline Age (N=703) & Frequency & Percentage \\
\hline Less than 20 yrs & 17 & $3.8 \%$ \\
\hline 20 to 25 yrs & 15 & $3.3 \%$ \\
\hline 25 to 30 yrs & 264 & $58.7 \%$ \\
\hline 30 to 35 yrs & 113 & $25.1 \%$ \\
\hline More than 35 yrs & 41 & $9.1 \%$ \\
\hline Education (n= 703) & Frequency & Percentage \\
\hline Upto Primary & 16 & $3.6 \%$ \\
\hline Senior secondary & 412 & $91.6 \%$ \\
\hline Higher secondary & 20 & $4.4 \%$ \\
\hline Undergraduate & 2 & $0.4 \%$ \\
\hline Caste (n=703) & Frequency & Percentage \\
\hline General & 43 & $9.6 \%$ \\
\hline OBC & 256 & $56.9 \%$ \\
\hline Schedule tribe & 87 & $19.3 \%$ \\
\hline Schedule cast & 64 & $14.2 \%$ \\
\hline Occupation(n=703) & Frequency & Percentage \\
\hline Skilled & 7 & $1.6 \%$ \\
\hline Unskilled worker & 443 & $98.4 \%$ \\
\hline SES (n=703) & Frequency & Percentage \\
\hline Medium(upper lower) & 2 & $0.4 \%$ \\
\hline High( upper middle) & 2 & $0.4 \%$ \\
\hline Low (upper lower) & 446 & $99.2 \%$ \\
\hline
\end{tabular}

In this cross sectional observation study, total 600 patients were recruited, out of these 450 were found eligible after meeting study inclusion criteria and required ICU / HDU admission.

In the above table shows the majority $264(58.7 \%)$ of the women were belonging to the age group between 25 to 30 years, majority $412(91.6 \%)$ women were belonged in the senior secondary school, majority $256(56.9 \%)$ of the women were other backward class, $443(98.4 \%)$ of the women were unskilled worker \& 446 $(99.2 \%)$ of the women were belonging to the upper lower socio economic status.

Table No. 2: Indication of ICU / HDU admission in the study subjects.

\begin{tabular}{|l|l|l|}
\hline ICU / HDU admission Indication & Frequency & Percentage \\
\hline Hypertensive disorder of pregnancy & 180 & $40.0 \%$ \\
\hline Hemorrhage in pregnancy & 128 & $28.4 \%$ \\
\hline Medical disorder of pregnancy & 108 & $24.0 \%$ \\
\hline Sepsis & 34 & $7.6 \%$ \\
\hline
\end{tabular}

In the above table shows that the 4 ICU / HDU admission indication. Out of these 600 women, majority $180(40.0 \%)$ of the women were Hypertensive disorder of pregnancy, followed by $128(28.4 \%)$ of the women were Haemorrhage in pregnancy, $108(24.0 \%)$ of the women were Medical disorder of pregnancy \& $34(7.6 \%)$ of the women were Sepsis.

Table No. 3: Maternal Outcome in the study subjects according their indication of ICU / HDU admission.

\begin{tabular}{|c|c|c|c|c|c|}
\hline \multirow[t]{2}{*}{ ICU / HDU admission Indication } & \multicolumn{5}{|l|}{ Maternal Outcome } \\
\hline & Shift to other Ward (Step Down) & Mortality & LAMA & Discharge & Shift to CCU \\
\hline Hypertensive disorder of pregnancy $(\mathrm{n}=180)$ & $142(78.9 \%)$ & $22(12.2 \%)$ & $4(2.2 \%)$ & $7(3.9 \%)$ & $5(2.8 \%)$ \\
\hline Haemorrhage in pregnancy $(\mathrm{n}=128)$ & $108(84.4 \%)$ & $6(4.7 \%)$ & $3(2.3 \%)$ & $10(7.8 \%)$ & $1(0.8 \%)$ \\
\hline Medical disorder of pregnancy $(\mathrm{n}=108)$ & $69(63.9 \%)$ & $7(6.5 \%)$ & $5(4.6 \%)$ & $26(24.1 \%)$ & $1(0.9 \%)$ \\
\hline Sepsis $(n=34)$ & $24(70.6 \%)$ & $4(11.8 \%)$ & - & $5(14.7 \%)$ & $1(2.9 \%)$ \\
\hline Total & $343(76.2 \%)$ & $39(8.7 \%)$ & $12(2.7 \%)$ & $48(10.7 \%)$ & $8(1.8 \%)$ \\
\hline
\end{tabular}

In the above table shows that the total maternal mortality was $8.7 \%$, out of these majority maternal mortality were hypertensive disorder of pregnancy. In these 8 were shifted to the Critical care unit due to hemodynamic instability, AKI OR MODS.

\section{DISCUSSION}

The ICU / HDU facility in department of obstetrics \& gynaecology in Chalmeda Anand Rao Institute of Medical
Sciences \& Hospital Karimnagar, Telangana consist of 15 beds each equipped with monitor and total three ventilators. It is efficiently managed by a dedicated team of gynaecologist, anesthesiologist, resident and nursing staff.

There total numbers of admission were 5598 of obstetrics \& gynaecology admitted in the institute. During this study period of 1 June 2019 to 31 March 2020, out of which 600 patient were admitted to ICU / 
HDU. 450 were admitted for obstetrical indication $\&$ also included for the purpose of the study. 150 were admitted for gynaecological indication \& were excluded for the study.

The ICU / HDU utilisation rate of admission was found 8.03 per 100 in this study. With comparable socioeconomic status, ICU / HDU utilisation was high in our study because we are in tertiary care center with major bulk of referrals. Limited accessibility \& higher morbidity prior receiving the patient to ICU / HDU explain the contradiction.

In this study shows that the majority $264(58.7 \%)$ of the women were belonging to the age group between 25 to 30 years, majority $412 \quad(91.6 \%)$ women were belonged in the senior secondary school, majority $256(56.9 \%)$ of the women were other backward class, $443(98.4 \%)$ of the women were unskilled worker \& 446 $(99.2 \%)$ of the women were belonging to the upper lower socio economic status.

In this study it shows that the 4 ICU / HDU admission indication. Out of these 600 women, majority $180(40.0 \%)$ of the women were Hypertensive disorder of pregnancy, followed by $128(28.4 \%)$ of the women were Hemorrhage in pregnancy, 108 $(24.0 \%)$ of the women were Medical disorder of pregnancy \& $34(7.6 \%)$ of the women were Sepsis. In this present study found that the $8.7 \%$ cases were maternal mortality.

Similarly Pattnaik $\mathrm{T}$ (13) found majority $79.6 \%$ of the patient belonged to the less than 30 years. Also found majority $25.9 \%$ of the patients were admitted of the hypertensive disorder of pregnancy, followed by the $29.6 \%$ of the patients were admitted of hemorrhage disorder of pregnancy, $27.6 \%$ of the patients were admitted of medical disorder of pregnancy $\& 11.1 \%$ of the patients were admitted of sepsis in ICU / HDU unit. Also Pattanaik T was found $16.6 \%$ of the maternal mortality. Also Veerbhadrappa ${ }^{(14)}$ shows that $76.2 \%$ of the patients were belonging to the less than 30 years. Also found that the more than
$89 \%$ of the women were literate which is similar to finding seen by Soumini $\mathrm{G}^{(15)}$, housewife $70 \%$. Eclampsia in hypertensive disorder of pregnancy was $18.0 \%$, haemorrhage disorder of pregnancy was $6.5 \%$ \& sepsis was $17.0 \%$ of the admitted women.

In the study was done by Poornima $\mathrm{B}^{(16)}$ was found $84.7 \%$ of the patients were low socioeconomic status. Which is similar finding seen by Shrestha D ${ }^{(17)}$, low socio economic status was $85.0 \%$. Similarly found to study Joshi PS ${ }^{(18)}$, pre-eclampsia accounted for $74(34.74 \%)$ but eclampsia were very high $173(61.56 \%)$ in contrary to this study were $20(9.38 \%)$, HELLP is also accounted so high $59(34.10 \%)$ in contrary to this study were 5 (2.34\%).

Also Veerbhadrappa ${ }^{(14)}$ shows that $52.0 \%$ of the patients were belonging to the hypertension disorder of pregnancy, $23.0 \%$ of the patients were belonging to the haemorrhage disorder of pregnancy. Which is similar finding seen by Shrestha D (17), hypertension disorder of pregnancy was $32.5 \%$, hemorrhage disorder of pregnancy was $42.5 \%$, in medical disorder of pregnancy was $7.5 \%$ \& Sepsis was $10.0 \%$ of the women for the indication of ICU / HDU admission.

\section{CONCLUSION}

In our study $8.03 \%$ utilisation rate of admission required ICU / HDU admission. Hypertensive disorder of pregnancy \& hemorrhage were the 2 major risk factor for ICU / HDU admission. Commonest cause of mortality was hypertensive disorder of pregnancy \& more than one diagnosis on admission was the other risk factors for ICU / HDU admission. A dedicated ICU / HDU will go a long way in reducing maternal mortality as the responses time from onset of acute severe illness to provision of high quality critical care will be substantially reduced. Establishment of ICU / HDU may help in earlier admission of moderately ill patient for better observation \& may also ICU admission. A multidisciplinary team approach with trained staff for timely 
quality management is mandatory in the care of obstetric emergencies. Hence the need for a dedicated obstetric ICU / HDU or critical care unit should be considered in every large public hospital \& every tertiary health care facilities catering to high risk pregnant women.

Acknowledgement: None

\section{Conflict of Interest: None}

\section{Source of Funding: None}

Ethical Approval: Approved

\section{REFERENCES}

1. Mahutte NG, Murphy-Kaulbeck L, Le Q, Solomon J, Benjamin A, Boyd ME. Obstetric admissions to the intensive care unit. Obstet Gynecol. 1999;94:2636.

2. Platteau P, Engelhardt T, Moodley J, Muckart DJ. Obstetric and gynaecological patients in an intensive care unit: A 1 year review. Trop Doct. 1997;27:202-6.

3. Gilbert TT, Smulian JC, Martin AA, Ananth CV, Scorza W, Scardella AT, et al. Obstetric admissions to the intensive care unit: Outcomes and severity of illness. Obstet Gynecol. 2003;102:897903.

4. Maternal Health. UNICEF INDIA. Accessed on 2016 Oct. Available from http://unicef.in/Whatwedo/1/MaternalHealth.

5. Fact Sheets. Maternal Mortality. World Health Organisation. Accessed on 2018 Feb. Available from https://www.who.int/ news-room/factsheets/detail/maternal-mortality.

6. Masood A., Gaballah K., Omar Z. Maternal and Foetal Outcome among patients requiring High Dependency Unit admission: A Five Year Prospective Study, Obstetrics and Gynecology International Journal. 2018 Feb 26; 9(I- 2018):89-93.
7. Bevan R, Venkatesh B, Freebairn R. Intensive Care Medicine Training in Australia and New Zealand: A Clarification, Critical Care Medicine. 2015 Nov; 43(11):e540.

8. Ryan M, Hamilton V, Bowen M, et al. The role of a high-dependency unit in a regional obstetric hospital, Anaesthesia. 2000; 55:1155-8.

9. Monsalve Germán A, Martínez Catalina M., Gallo Tatiana, González María Virginia, Arango Gonzalo, Upegui Alejandro et al . Maternal Critical Care: Outcomes and Patient Characteristics in a Combined Obstetric High Dependency Unit in Medellín, Colombia, Rev. Colomb. Anestesiol. 2011 July; 39(2): 190-205.

10. Saravanakumar K, Davies L, Lewis M, Cooper GM. High dependency care in an obstetric setting in the UK. Anaesthesia. John Wiley \& Sons, Ltd (10.1111); 2008.

11. Levels of critical care for adult patients, Nursing in Critical Care. 2003 Apr; 8(2):90.

12. Guidelines for the Critically Ill Woman in Obstetrics Version 1.1 2014, Aug: 7.

13. Pattanaik T, Samal S, Behuria S. Obstetric admissions to the intensive care units: A five year review, International Journal of Reproduction, Contraception, Obstetrics and Gynaecology. 2015 Dec; 6:1914-1917.

14. Veerabhadrappa VK, Shivanagappa M Mahadevaiah M, Srikanth SM et. al. Maternal outcome in obstetric ICU and HDU: a study from a teaching hospital in South India. Int. J Reprod Contracept Obstet Gynaecol 2019; 8: 862 - 8.

15. Soumini G, Harini. Study of obstetric ICU admissions and maternal outcome. International Journal of Medical and Health Research. October 2017; Vol. 3. Issue 10; 117-120.

16. Bhat BPR, Nevada MH, Rao SV \& Nagarathna G. Evaluation of Obstetric admission to intensive care unit of a tertiary referral centre coastal India. 
Tulasi Reddy et.al. Clinical characteristics and maternal outcome of obstetrics patients admitted to the intensive care unit: cross sectional observational study.

Indian J Crit Care Med. 2013 Jan - Feb; 17 (1): 34 - 37.

17. Shrestha, D., Aryal, S., \& Baniya, S. Evaluation of Clinical Characteristics and Outcomes of Obstetric Patients Admitted to Intensive Care Unit: A case control study. Journal of Lumbini Medical College, 2018; 6(1), 11 - 16.

18. Joshi PS, Kathaley MH, Dashrathi RU \& Prasade SU. Study of maternal and Perinatal Outcome in Patients in High Dependency Unit (HDU) in a Tertiary
Care Centre. MVP J. Med. Sci. 2019; 6(1): $78-83$.

How to cite this article: Reddy T, K. Rekha Rani, M. Chandramathi et.al. Clinical characteristics and maternal outcome of obstetrics patients admitted to the intensive care unit: cross sectional observational study. Gal Int J Health Sci Res. 2021; 6(2): 1-6. DOI: https://doi.org/10.52403/gijhsr .20210401 